\title{
DAVID JACKSON
}

Scholz omitted crucial parts of the the recent history of the seismic gap forecast and test. He remarked that our test of the gap theory was 'flawed' because it used earthquakes 'smaller than system-sized'. This was also asserted in a published comment by Nishenko \& Sykes 1 and answered by Jackson \& Kagan². But 'system-sized' was never defined in the original seismic gap model $\stackrel{3}{\text {. }}$.

The model was widely used to estimate potential for earthquakes of magnitude 7.0 and larger, so we used this threshold in our original test. The results of our test were essentially unchanged if we used larger events (magnitude 7.5 and above) as recommended by Sykes \& Nishenko. More importantly, a revised version of the seismic gap model has been published 4 that is much more specific and defines the magnitude of earthquake appropriate to each seismic zone. Nishenko deserves much credit for stating the seismic gap model in testable form. Unfortunately the new gap model also failed $\underline{5}$ because it predicted far more earthquakes than observed in the following five-year period. Now 10 years have elapsed with the same result.

Defining the 'system-sized' magnitude is a fundamental difficulty, not a semantic issue. Small earthquakes are clearly clustered, but the seismic gap model posits that large 'system-sized' events have the opposite behaviour. The definition becomes important because some different physics must take over for large events if the gap hypothesis is true. The same difficulty exists for the sand-pile analogy, whether or not it describes earthquake behaviour well. Small areas on the surface of a sand pile can suffer 'sandslides' even if they are not locally at a critical slope, because slope failures above or below can affect them. Scholz's argument that a local area might become immune by having recently slipped assumes that it is big enough to preclude upslope or downslope failures. Identifying that particular size requires a knowledge of the state of the whole system, which is not available in the earthquake analogy. The seismic gap model has no meaning without a definition of 'system-sized', and the model fails with the only specific definition offered so far.

David D. Jackson

Southern California Earthquake Center,

University of California,

Los Angeles, CA 90095-1567

USA

1. Nishenko, S.P. \& Sykes, L.R. Comment on 'Seismic gap hypothesis: ten years after' by Y.Y. Kagan and D.D. Jackson. J. Geophys. Res. 98, 9909-9916 (1993).

2. Jackson, D.D. \& Kagan, Y.Y. Reply to Nishenko and Sykes. $J$. Geophys. Res. 98, 9917-9920 (1993).

3. McCann, W.R., Nishenko, S.P., Sykes, L.R. \& Krause, J. Seismic gaps and plate tectonics: seismic potential for major boundaries. Pure Appl. Geophys. 117, 1082-1147 (1979).

4. Nishenko, S.P. Circum-Pacific seismic potential: 1989-1999. Pure Appl. Geophys. 135, 169-259 (1991).

5. Kagan, Y.Y. \& Jackson, D.D. New seismic gap hypothesis: five years after. J. Geophys. Res. 100, 3943-3960 (1995). 